\title{
Orman fidanlıklarında yabancı otlarla mücadelede EFRICAD ekipmanı kullanımının maliyet analizi
}

\author{
Cost analysis of EFRICAD equipment used for weed control in the forest nurseries
}

\author{
Emre GÖKSU' \\ Salih PARLAK ${ }^{2}$ \\ Zülfü BOZA ${ }^{1}$
}

${ }^{1}$ Ege Ormancılık Araștırma Enstitüsü Müdürlüğü, İzmir

${ }^{2}$ Bursa Teknik Üniversitesi, Orman Fakültesi, Bursa

Sorumlu yazar (Corresponding author) Emre GÖKSU

emregoksu@ogm.gov.tr

Geliş tarihi (Received)

19.12.2018

Kabul Tarihi (Accepted)

22.02.2019

Atıf (To cite this article): GÖKSU, E, PARLAK, S , BOZA, Z . (2019). Orman fidanlıklarında yabanc1 otlarla mücadelede EFRICAD ekipmanı kullanımının maliyet analizi. Ormancılık Araştırma Dergisi, 6 (1), 87-95. DOI: https://doi.org/10.17568/ogmoad.499203

\begin{abstract}
$\ddot{O} \mathbf{z}$
Geniş bir yüz ölçümüne sahip orman fidanlıklarında yabancı otlarla etkin mücadele yapılabilmesi modern mekanizasyon tekniklerinin kullanılmasını zorunlu kılmaktadır. Bu çalışmada, geliştirilen EFRICAD (Ege Forestry Research Institute Computer Aided Design) ekipmanı ile yastıklarda fidan sıra aralarının kolay ve hızlı bir şekilde ilaçlanarak yabancı otlarla çok daha ekonomik ve etkili bir mücadelenin yapılması hedeflenmiştir. Günümüzde orman fidanlıklarında kullanılan bu tür çekilebilir tip yastık ilaçlama ekipmanı bulunmamaktadır. Bu bağlamda Muradiye (Manisa) Orman Fidanlık Şefliği'nde denemeleri gerçekleştirilen EFRICAD ekipmanının maliyet analizi yapılmış ve geleneksel mücadele yöntemlerinin maliyetleri ile karşılaştırılarak sağladığ 1 ekonomik getiriler hesaplanmıştır. Fidanl1k üretim programında yer alan 50 dekar (da) alanda $1+0$ yaşındaki çıplak köklü fidanların bulunduğu yastıklarda yabancı otlarla mücadelede EFRICAD ekipmanı kullanılarak gerçekleşen maliyetlere kıyasla Orman Genel Müdürlüğü (OGM) tarafından belirlenen maliyetlerin 11,94 kat; yöresel koşullara göre belirlenen maliyetlerin ise 12,56 kat fazla olduğu saptanmıştır. EFRICAD ekipmanının orman fidanlıklarında kullanılması ile işletme kaynaklarının etkin ve verimli bir şekilde yönetilmesi sağlanarak fidan yastıklarındaki yabanc1 otlarla mücadelenin daha ekonomik olarak gerçekleştirilebileceği ortaya konulmuştur.
\end{abstract}

Anahtar Kelimeler: Orman fidanlıkları, yabancı otlar, yastık ilaçlama ekipmanı, maliyet analizi

\begin{abstract}
In the forest nurseries with a large area, the effective weed control necessitates the use of modern mechanization techniques. In this study, we aimed at fighting against the weeds in seedbeds easily and quickly and in a more economical and effective way with the development of EFRICAD (Aegean Forestry Research Institute Computer Aided Design). There is no such a trailer type-seedbed spraying equipment that is used in the forest nurseries today. In this context, the EFRICAD equipment was tested in the Muradiye (Manisa) Forest Nursery, and cost analysis was performed and by comparing the cost of existing control methods, the economic returns of the equipment were calculated. Results of the plot application in a 50-decare (da) area in the nursery production program showed that the costs calculated in nursery for weed control on $1+0$ year old bare-root seedlings, were 11.94 times higher in General Directorate of Forestry (GDF) unit prices and 12.56 times higher in local market conditions than the use of EFRICAD equipment. As a result, we suggest that using EFRICAD equipment on seedling beds in the forest nurseries for weed control will provide more efficient and productive results.
\end{abstract}

Keywords: Forest nurseries, weeds, seedbed-spraying equipment, cost analysis 


\section{Giriş}

Türkiye'de ağaçlandırma, rehabilitasyon ve yanan orman alanlarının ağaçlandırılması faaliyetlerinde kullanılan fidanların üretiminin hemen hemen tamamı OGM tarafından işletilen 3.264 ha alana kurulu ve kapasitesi 322,2 milyon adet/y1l olan 131 orman fidanlığında yapılmaktadır (Anonim, 2018). Fidanlıklarda yabancı otlarla mücadele mekanik ve kimyasal olmak üzere iki farklı yöntemle yapılabilmekte, yaygın olarak mekanik mücadele yöntemi uygulanmaktadır. Fidanların çimlenmeye başlamasıyla birlikte yastıklarda yabani otlar da belirmeye başlamakta ve bu aşamada yapılan bir müdahale otların kökünden alınmasını mümkün hâle getirmektedir (Alkan, 2003). Türkiye'de gerek devlet gerekse özel sektörün işlettiği fidanlıklarda mekanik yöntemler uygulanarak çok sayıda işçi kullanılmasına rağmen, fidanlar çoğunlukla otlar içinde kaybolmakta, fidan gelişimi büyük ölçüde zayıf kalmaktadır. Hatta büyük fidanlıklarda parselin bir ucu temizlenirken diğer ucu otla kaplanmaktadır. Bazen sonuncu parsele sıra gelene kadar fidanlar gelişme kaybına uğramaktadır. Bu arada otların kökleri de daha derinlere gittiğinden çıkarma esnasında fidanlar büyük zarar görmekte ve sararmalar meydana gelmektedir. Küçük fidanlarda ise çoğu defa özellikle acemi işçilerin körpe fidanları otlarla birlikte çıkardıkları da gözlenmektedir (Ürgenç, 1998).

Literatürde orman fidanlıklarında yabancı otlarla mücadele çalışmalarında ekipman kullanımı ile ilgili çalışmalara çok az rastlanılmıştır. İlter ve ark. (1988), orman fidanlıklarında fidan üretim sürecindeki iş ögelerinin yapılmasında kullanılan makine ve iş gücü ile yürütülen işlemlerin birim zamanları ve maliyetlerini hesaplamışlardır. Türkiye'deki çeşitli fidanlıklarda yapılan ölçümlerde maliyetlerin her bir fidanlık için farklı olduğu görülmüştür. Alkan (2003) ise fidanlık yöneticilerinin \%87,5'inin ot alma giderlerinin fidan maliyeti üzerindeki payını çok önemli bulduğunu belirterek fidanlıklarda makineli çalışmanın hem maliyetler hem de verimlilik bakımından insan gücüne göre daha avantajlı sonuçlara neden olduğunu vurgulamiştır. Acar ve ark. (2004), devlet orman fidanlık işletmelerinde maliyet yönetiminin etkin şekilde uygulanabilirliği üzerine gerçekleştirdikleri çalışmalarında en önemli maliyet unsurunun işçilik giderleri olduğunu belirterek işlem maliyetlerinin önem sıralamasında iş gücünün yoğun bir şekilde kullanıldığ 1 ot alma giderlerinin ilk sirada yer aldığını ortaya koymuşlardır. Kavgacı ve ark. (2018) da fidanlıklarda yabancı otlarla mücadele yöntemlerinin belirlenmesi ve kullanılan yöntemlerin fidanlık maliyetlerine katkılarının araştırılması amaciyla Eğirdir (Isparta) ve Antalya Orman Fidanlıklarında yaptıkları çalışmalarında, pulvarizatörle herbisit uygulamasının elle ot alma ve solarizasyon yöntemlerinden daha ekonomik olduğunu belirtmişlerdir.

Tüm işletmelerde olduğu gibi fidanlık işletmelerinin de amaçlarından biri, sahip olduğu üretim ögelerini etkin ve verimli bir şekilde kullanarak en fazla net geliri elde etmektir. Bu amaca ulaşmak için fidan üretiminde en önemli gider kalemlerinden birini oluşturan yabancı otlarla mücadelede maliyetlerin düşürülmesi ile birlikte fidanlıklarda ot alımlarının ve fidan bakımlarının zamanında yapılması sağlanarak yabancı ot rekabetinin erken dönemde engellenmesi ve daha kaliteli fidan yetiştirilmesi gerekmektedir. Dolayısıyla fidanlıklardaki yabancı otlarla daha etkin ve ekonomik bir mücadele yapılması maksadiyla yastıkta yetiştirilen fidanlarla rekabete girerek büyüme ve kalitesini olumsuz etkileyen yabanc1 otlarla kimyasal yoldan mücadele edilmesi ve yapılacak mücadelenin yetiştirilen fidanlara zarar vermeden yastıkların ilaçlanmasına imkân verecek bir ekipmanın geliştirilmesi hedeflenmiştir. Bu çalışmada, devlet orman fidanlıklarında fidan sıra aralarında bulunan yabancı otların sökülmesi için işgücü, ilaçlanması için ise çekilebilir tip ekipman olmak üzere iki farklı mücadele yöntemi uygulanmış ve maliyet unsurları karşılaştırılmıştır (Boza ve ark., 2017).

\section{Materyal ve Yöntem}

\section{1. Çalışma alanı}

Çalışma konusu makinenin imalatı Muradiye Sanayi Bölgesinde (MSB) gerçekleştirilmiş, denemeler ise Manisa ili Yunusemre ilçesi, Muradiye Mahallesi sınırları içerisinde yer alan İzmir Orman Bölge Müdürlüğü'ne bağlı Muradiye Orman Fidanlık Şefliği’nde yapılmıştır. Türkiye'deki en fazla çıplak köklü orman fidanı yetiştirme kapasitesine sahip ve en büyük orman fidanlıklarından biri olan Muradiye Orman Fidanlık Şefliği’nin genel alanı 1.009 da ve rakımı $27 \mathrm{~m}$ olup $38^{\circ} 38^{\prime} \mathrm{K}$ ve $27^{\circ} 17^{\prime} \mathrm{D}$ koordinatlarında yer almaktadır. Y1llık fidan üretim kapasitesi 5.000.000 adet/yıl olup yaklaşık 3.100 .000 adedini ekim yastıklarındaki çıplak köklü ve 1+0 yaşında olan fistıkçamı, kara servi, yalancı akasya, çınar ve diğer yapraklı türler oluşturmaktadır (Boza ve ark., 2017).

Denemelerin bu fidanlıkta yapılmasında ekipman yapım maliyetlerinin fidanlık alanına en yakın sanayi bölgesi olan MSB'de düşük olması, gerek üretim-montaj aşamalarında gerekse ekipmanı geliştirme aşamasında yapılacak değişikliklere müdahale etme olanağının bulunması ve böylece 
fidanlıkta yapılan denemelerin aksatılmadan yürütülmesi gibi faktörler etkili olmuştur.

\subsection{EFRICAD ekipmanını geliştirmede kullanılan materyaller}

EFRICAD ekipmanının çalışma prensibi, sade- ce fidan sıra aralarındaki yabancı otları ilaçlayıp öldürmeye yönelik olarak tasarlanmıştır (Şekil 1). Ekipmanın imalatı; oluşturulan tasarımların teknik çizimleri, üretici firmayla yapılan mühendislik çalışmaları, benzer ekipmanların incelenmesi, fidanlıkta yapılan denemeler ve ölçümler sonucu gerekli değişiklikler yapılarak gerçekleştirilmiştir.

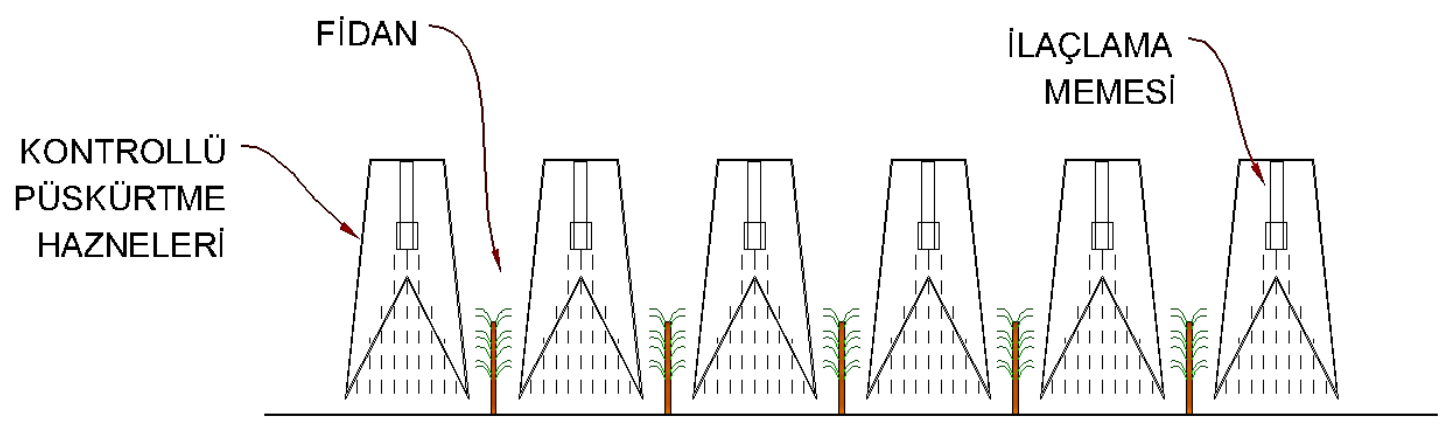

Şekil 1. EFRICAD ekipmanının tasarımında kullanılan ilaçlama prensibi Figure 1. Spraying principle used for designing the EFRICAD equipment

Çalışmaya konu olan makinenin teknik çizimleri ve hesaplamaları proje ekibi tarafından yapılmıştır. Ekipman parçalarının iki boyutlu çizim ve 3D modellemelerinde AutoCAD3D deneme sürümü kullanılmıştır (Şekil 2). CAD (Computer Aided Design) yazılımı, iki boyutlu ve üç boyutlu çizim, modelleme ve sunum yapabilme yeteneğine sahip bilgisayar destekli bir yazılımdır. Ayrıca gerek duyulduğunda veri dönüştürme, malzeme kütüphanesi, veri alışverişi ve görselleştirme desteği için deneme sürümü bilgisayar programları kullanılmıştır. AVI (Audio Video Interleaved) uzantılı videoların düzenlenip yönetilmesi ve yeniden sunuma hazırlanmasında deneme sürümü multimedya programlarından faydalanılmıştır (Boza ve ark., 2017).

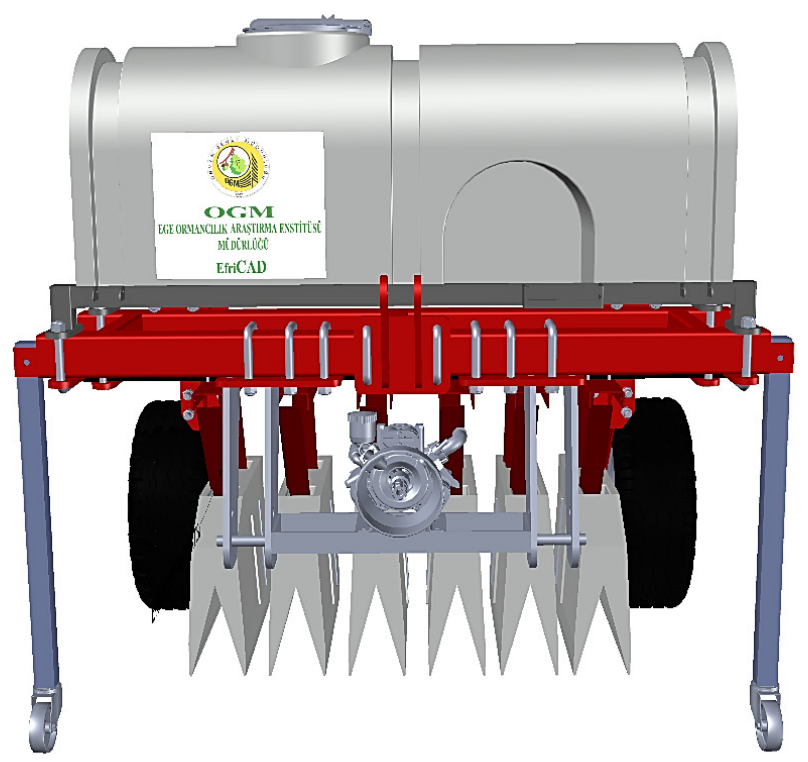

Şekil 2. EFRICAD ekipmanı tasarımı teknik çiziminin önden görünümü Figure 2. Front view of technical drawing of the EFRICAD equipment design 


\subsection{Yabancı otlarla mücadelede iş gücü ve ekipman masraflarını hesaplama yöntemi}

Yabancı otlarla mücadelede iş gücü masraflarının hesaplanmasında 2016 yılı için OGM tarafından belirlenen işçi çalışma zamanı (IÇZ) ve işçi birim maliyeti (İBM) kullanılmıştır. Yöresel koşulların dikkate alınmasıyla oluşturulan iş gücü masraflarını hesaplamada ise zaman etüdü yöntemi kullanılarak elde edilen İÇZ ile İBM'nin çarpımı sonucu birim fiyatlar (TL/da) bulunmuştur (Boza ve ark., 2017).

EFRICAD ekipmanı için OGM tarafından herhangi bir standart zaman ve birim maliyet belirlenmediği için bu değerler ayrıca hesaplanarak elde edilen bulgular birim fiyat analizlerinde kullanılmıştır. Analizlerde kullanılan İBM, traktör birim maliyeti (TBM) ve geliştirilen ekipmana ilişkin maliyet hesaplamaları içerisinde genel üretim giderleri de yer almaktadır.

Birim fiyatın hesabı aşağıda belirtilen Formül 1'e göre bulunmaktadır:

$\mathrm{BF}=\mathrm{BM} \times \mathrm{SZ}$

Formül (1)

$\mathrm{BF}=$ Birim fiyat $(\mathrm{TL} / \mathrm{da})$,

$\mathrm{BM}=$ Yapılan işe ait saatlik birim maliyet (TL/sa.),
$\mathrm{SZ}=$ Yapılan işe ait işçi veya makine standart çalışma zamanı (sa./da) ile gösterilmektedir.

Muradiye Orman Fidanlık Şefliği'nde 2016 yılı için bir vejetasyon döneminde 50 da alanda $1+0$ yaşında çıplak köklü fidan üretimi yapılmaktadır. Yapılan denemeler sonucu ortaya çıkan iş gücüne ve EFRICAD ekipmanına ait birim fiyatlar ve 50 da alan için oluşan masraflar karşılaştırılmıştır.

\subsection{1. İș gücü masraflarının hesaplama yöntemi}

Çalışmada OGM'nin belirlediği iş gücü ile yapılan yabanc1 otlarla mücadelede, "direk malzeme giderleri (bağ bıçağ1, eldiven, ot toplama sepeti)" ve "ücret ve maaş giderleri" toplamı maliyet hesaplamasında dikkate alınmıştır. İşçilik ücretinde 2016 yılına ait OGM birim fiyatları, diğer malzeme ve ekipman fiyatlarında ise 2016 yılı piyasa fiyatları kullanılmıştır.

Hesaplamalarda işçilerin kullandığ ve koruyucu malzeme amaciyla alınan eldivenlerin kullanım ömürleri 1 ay (192 sa.) olarak değerlendirilmiş ve yedeklerinin bulundurulacağ 1 varsayılmıştır. Plastik ot toplama sepetinin kullanım ömrü ise 2 ay (384 sa.) olarak hesaplamalara dâhil edilmiştir. Tablo 1'de iş gücü ve ekipmana ilişkin maliyet bedeli hesabı gösterilmektedir.

Tablo 1. İş gücü ve ekipmanlara ait birim maliyet bedeli

Table 1. Unit cost value for labor and equipment

\begin{tabular}{lr}
\hline Maliyet unsurlar1 & Saat maliyetleri (TL/sa.) \\
\hline A. Direkt malzeme giderleri & \\
\hline Bağ bıçağ1 & $(2$ adet x $2 \mathrm{TL}) / 192 \mathrm{sa} .=0,021 \mathrm{TL} / \mathrm{sa}$. \\
Eldiven & $(2$ çift x $3 \mathrm{TL}) / 192 \mathrm{sa} .=0,031 \mathrm{TL} / \mathrm{sa}$. \\
$\begin{array}{l}\text { Ot toplama sepeti } \\
\text { Toplam }\end{array}$ & $(1$ adet x $40 \mathrm{TL}) / 384 \mathrm{sa} .=0,104 \mathrm{TL} / \mathrm{sa}$. \\
\hline B. Ücret ve maaş giderleri & 0,16 TL/ sa. \\
\hline İşçilik ücreti (Anonim, 2016 rayiç bedeli) & $6,98 \mathrm{TL} / \mathrm{sa}$. \\
Toplam & $6,98 \mathrm{TL} / \mathrm{sa}$. \\
\hline Genel toplam (A+B) & $\approx 7,14 \mathrm{TL} / \mathrm{sa}$. \\
\hline
\end{tabular}

*Rakamların toplamı yuvarlama yapılarak verilmiştir

Yabanc1 otlarla mücadelede elle yolma şeklinde köküyle sökülemeyen veya elle alınamayacak kadar küçük olan yabancı otlar kısa bir süre sonra tekrar büyüyerek baskın hâle gelebilmekte ve söküm esnasında toprakla birlikte çıkabilmektedir (Parlak, 2016). Mekanik mücadelede ise yabancı otların tamamını kökünden çıkarma imkânı olmadığından daha sık aralıklarla mücadele edilmesi gerekmektedir. Muradiye Orman Fidanlık Şefliği'nde bir vejetasyon döneminde aynı sahada iş gücü ile ot mücadelesi beş tekrarlı yapılmaktadır. $\mathrm{Bu}$ nedenle iş gücü ile yabancı otlarla mücadelede bir dönem içinde gerçekleşen masrafları bulabil- mek için hesaplanan birim fiyatın beş katı alınmıştır (Boza ve ark., 2017).

\subsubsection{EFRICAD ekipman masraflarını hesaplama yöntemi}

EFRICAD ekipmanına ilişkin birim fiyatın hesaplanmasina:

- OGM tarafından belirlenen zirai traktör (makine) maliyetleri,

- EFRICAD ekipmanının maliyeti, 
- Vasıflı işçi olan operatörün ve vasıfsız işçi olan yardımcısının maliyetleri,

- İlaç maliyeti toplamı dâhil edilmiştir.

Traktör ve işçilerin maliyetlerinde OGM'nin 2016 yılı için belirlediği birim maliyetler kullanılmıştır (Anonim, 2016). Amortisman bedeli ve oranlar1 ise 333 ve 345 say1l Vergi Usul Kanunu Genel Tebliğlerinden (Anonim, 2004 ve Anonim, 2005) alınmıştır. Tablo 2'de EFRICAD ekipmanına ilişkin maliyet bedeli hesabı gösterilmiştir.

Tablo 2. EFRICAD ekipmanına ilişkin birim maliyetler

Table 2._Unit costs for the EFRICAD equipment

\begin{tabular}{lr}
\hline Maliyet unsurları & Maliyet bedelleri \\
\hline A. Satın alma bedeli & $18.400 \mathrm{TL}$ \\
B. Hurda değeri (A*\%10) & $1.840 \mathrm{TL}$ \\
C. Amortismana tabi değer (A-B) & $16.560 \mathrm{TL}$ \\
D. EFRICAD Amortisman süresi & 5 yıl (10.000 sa.) \\
E. Faiz oranı & $720 \mathrm{TL}$ \\
F. Lastik satın alma bedeli (2 adet) & 2 yıl (4.000 sa.) \\
G. Lastik kullanım süresi & $1,66 \mathrm{TL} / \mathrm{sa}$. \\
\hline Sabit giderler & $0,83 \mathrm{TL} / \mathrm{sa}$. \\
\hline Amortisman (A-B)/10.000 & $0,28 \mathrm{TL} / \mathrm{sa}$. \\
Faiz (C*\%10)/10.000 & $2,77 \mathrm{TL} / \mathrm{sa}$. \\
Sigorta vb. giderler (A*\%3)/2.000 & Saatiyetleri (TL/sa.) \\
Toplam (TL/sa.) & $0,46 \mathrm{TL} / \mathrm{sa}$. \\
\hline Değişken giderler & $0,18 \mathrm{TL} / \mathrm{sa}$. \\
\hline Bakım ve onarım (A*\%5)/10.000 & $0,64 \mathrm{TL} / \mathrm{sa}$. \\
Lastik masrafı (F/4.000) & $\approx 3,41 \mathrm{TL} / \mathrm{sa}$. \\
Toplam (TL/sa.)
\end{tabular}

\subsection{Fidan kayıp oranlarını belirleme yöntemi}

Fidanların kayıp oranlarının belirlenmesi için bu denemeler, ekipmanın mekaniğine uygun tesis edilen ve daha önceden yabancı otla mekanik mücadele yapılmamış olan katalpa (Catalpa bignonioides) yastıklarında gerçekleştirilmiştir. İlk olarak ilaçlama ekipmanının tankına çivit boya maddesi konarak sonrasında yeşil aksamdan alınan sistemik etkili bir herbisit olan ve etken maddesi litrede 441 g Glyphosate potasyum tuzu içeren yabancı ot ilac1 kullanılarak uygulamalar yapılmıştır. Çalışma alanı için seçilen Muradiye Orman Fidanlık Şefliği'nde baskın yabancı otlar semizotu (Portulaca oleracea) ve topalak (Cyperus rotundus) türleri olduğundan, denemede kullanılan ilacın seçiminde mücadele edilecek türler belirleyici olmuştur. İlaçlama uygulaması sonucunda hem fidanlara ilacın bulaşıp bulaşmadığı, hem de yabancı ot çıkış1nın tekrarlanıp tekrarlanmadığı gözlenmiştir.

\section{Bulgular}

\subsection{Yabancı otlarla mücadele faaliyetlerine ilişkin masraflar}

\subsection{1. İş gücü masrafları}

Ot alma sırasında işçinin bir yardımcıya ihtiyaç duymadan tek başına çalışabileceği düşünülmüş, işçi vasfı olarak ise "vasıfsız işçi” alınmıştır. Buna göre vasıfsız işçinin, ot yoğunluğu \%40 ve daha az olduğu sahalar için yastıklardaki fidan sıra aralarında ve altlarında bulunan yabancı otları sökmesi ve sökülen otları toplayarak belirlenen yerlere depolaması işi için;

- OGM tarafından belirlenen İÇZ değeri: 60 sa./ da (Anonim, 2016),

- Yöresel koşullara göre belirlenen İÇZ değeri: 62,89 sa./da (Boza ve ark., 2017),

- İBM: 7,14 TL/saattir (Tablo 1).

a. OGM tarafından belirlenen iş gücü ile ot alma işi birim fiyatı:

Bir kez için;

$\mathrm{BF}=60 \mathrm{sa} . / \mathrm{da} \times 7,14 \mathrm{TL} / \mathrm{sa} .=428,40 \mathrm{TL} / \mathrm{da}$,

Beş kez için;

$\mathrm{BF}=428,40 \times 5=2.142,00 \mathrm{TL} / \mathrm{da}$,

b. Yöresel koşullara göre belirlenen iş gücü ile ot alma işi birim fiyatı:

Bir kez için;

$\mathrm{BF}=62,89 \mathrm{sa} . / \mathrm{da} \times 7,14 \mathrm{TL} / \mathrm{sa} .=449,04 \mathrm{TL} / \mathrm{da}$, 
Beş kez için;

$\mathrm{BF}=449,04 \times 5=2.245,20 \mathrm{TL} / \mathrm{da}$

olarak hesaplanmıştır.

\subsubsection{EFRICAD ekipmanının masrafları}

EFRICAD ekipmanının bağlanacağ 55 beygir (55 HP) gücündeki traktörü ve ekipmanı kullanacak vasıflı işçinin İBM'si 2016 yılı OGM rayiç bedellerine göre TBM 46,41 TL/sa.; vasıflı işçi İBM'si 14,25 TL/saattir. EFRICAD ekipmanının saatlik birim maliyeti ise 3,41 TL/sa. (Tablo 2) olarak hesaplanmıştır.

İlaçlama birim fiyatını (İLBF) belirlemek amacıyla yapılan hesaplamalarda 1 da alanın ilaçlanması için $600 \mathrm{ml}$ ilaç gerektiği tespit edilmiştir. Piyasa araştırmasına göre ise bir litre ilacın değerinin ortalama 19 TL olduğu belirlenmiştir. Buna göre 600 $\mathrm{ml}$ ilacın birim fiyatı 11,40 TL/da bulunmuştur.

EFRICAD ekipmanı ile yabancı otları ilaçlama işi için bir traktör operatörü (vasıflı işçi) ve yardımcısı (vasıfsız işçi) olmak üzere iki kiși görevlendirilmiştir. Vasıfsız işçinin birim maliyeti (ücret ve maaş giderleri) 6,98TL/saattir (Tablo 1). Dolayısıyla İBM 14,25 TL/sa. +6,98 TL/sa. = 21,23 TL/sa. alınmıştır. Boza ve ark.'na (2017) göre, mücadele yapılacak alanın büyüklüğüne bağlı olarak değişmekle birlikte, EFRICAD ekipmanının 50 da'lık deneme alanını ilaçlaması dikkate alınarak hesaplanan birim alandaki standart zamanı ortalama 2,17 sa./da'dır. Ekipman birim fiyatını hesaplamada Formül 2 kullanılmıştır.

$$
\begin{array}{lr}
\mathrm{BF}=(\mathrm{TBM} \times \mathrm{SZ})+(\text { EFRICAD BM x SZ })+(\dot{\mathrm{IBM}} \\
\mathrm{x} \mathrm{SZ})+(\text { İLBF }) & \text { Formül }(2)
\end{array}
$$

2 No.lu formülde ilgili değerler yerine konduğunda 1,0 da alandaki EFRICAD ile çalışmanın birim fiyatı ortalaması;

$\mathrm{BF}=(46,41 \times 2,17)+(3,41 \times 2,17)+(21,23 \times 2,17)+$ $11,40=165,58 \mathrm{TL} /$ da olarak hesap edilmiştir.

Elde edilen sonuçlara göre, yastıklardaki fidan sıra aralarında bulunan yabancı otlarla mücadele işleri için iş gücü ve geliştirilen EFRICAD ekipmanına ait hesaplanan birim fiyatların karşılaştırılması Tablo 3’te verilmiştir. Buna göre OGM birim fiyatları, EFRICAD ekipmanının hesaplanan birim fiyatlarından 11,94 $(\% 119,37)$ kat, yöresel koşullara göre hesaplanan birim fiyatlar ise 12,56 (\%o125,60) kat fazladır. İş gücü ile EFRICAD ekipmanı arasında oluşan birim fiyat farkının temel sebebi, çalışma yapılacak sahaya iş gücü ile beş kez girilmesine karşın EFRICAD ekipmanı ile sadece bir kez girilmesinin yeterli olmasidır.

Muradiye Orman Fidanlık Şefliği üretim programında bir vejetasyon döneminde $1+0$ yaşın-

Tablo 3. Yabancı otlarla mücadele faaliyetlerine göre birim fiyatların karşılaştırılması Table 3. Comparison of unit prices according to weed control activities

\begin{tabular}{lcccc}
\hline $\begin{array}{l}\text { Ot mücadelesi } \\
\text { faaliyet türü }\end{array}$ & $\begin{array}{c}\text { Hesaplanan birim fiyat } \\
(\mathrm{TL} / \mathrm{da})\end{array}$ & $\begin{array}{c}\text { Çalışma tekrar1 } \\
(\mathrm{adet})\end{array}$ & $\begin{array}{c}\text { Toplam birim fiyat } \\
(\mathrm{TL} / \mathrm{da})\end{array}$ & $\begin{array}{c}\text { EFRICAD’e göre } \\
\text { birim fiyat fark1 } \\
(\%)\end{array}$ \\
\hline OGM & $(1)$ & 5 & $(2 \times 3)$ & 119,37 \\
Yöresel & 428,40 & 5 & $2.142,00$ & 125,60 \\
EFRICAD & 449,04 & 1 & $2.245,20$ & --- \\
\hline
\end{tabular}

daki fidan üretimi 50 da alan için planlandığından, Tablo 4'te de belirtildiği gibi OGM birim fiyatlarina göre toplamda ortalama 107.100,00 TL masraf yapılacaktır. Yöresel koşullara göre hesaplama yapıldığında bu rakam ortalama 112.260,00 TL olacaktır. EFRICAD ekipmanı ile toplam ortalama masraf ise 8.279,00 TL olarak hesaplanmıştır.

Tablo 4. Yabancı otlarla mücadele faaliyetlerine göre masrafların karşılaştırılması Table 4. Comparison of costs according to weed control activities

\begin{tabular}{lcccc}
\hline $\begin{array}{c}\text { Ot mücadelesi } \\
\text { faaliyet türü }\end{array}$ & $\begin{array}{c}\text { Toplam } \\
\text { birim fiyat } \\
(\mathrm{TL} / \mathrm{da})\end{array}$ & $\begin{array}{c}\text { Çalışlacak alan } \\
\text { miktar1* } \\
(1)\end{array}$ & $\begin{array}{c}\text { Toplam } \\
\text { masraf } \\
(\mathrm{da})\end{array}$ & $\begin{array}{c}\text { EFRICAD'e göre mas- } \\
\text { raflar arasındaki fark } \\
\text { (TL) }\end{array}$ \\
\hline OGM & $2.142,00$ & 50 & $107.100,00$ & $98.821,00$ \\
Yöresel & $2.245,20$ & 50 & $112.260,00$ & $103.981,00$ \\
EFRICAD & 165,58 & 50 & $8.279,00$ & ---- \\
\hline
\end{tabular}

* 50 da alan, işçilerin ve makine/ekipmanın çalıșacağı brüt alan miktarıdır. Fidanlık uygulamalarında iș-zaman analizleri ve maliyet hesapları brüt alan üzerinden yapılmaktadır (Anonim, 2016). 


\subsection{Ekipman kullanımı ile meydana gelen fidan kayıpları}

Fidan yastıklarında ekim düzgün yapıldığı takdirde ekipmanın kontrollü püskürtme hazneleri fidan sıra aralarını ilaçlayacak, ilerleme esnasında ilacın fidana bulaşması önlenmiş olacaktır. Boyalı su ile yapılan denemede, sıra arası ekimin düzgün yapıldığ 1 yerlerde fidanlara boyalı su bulaşma ihmal edilebilir düzeyde (\%1-\%3) kalmıştır.

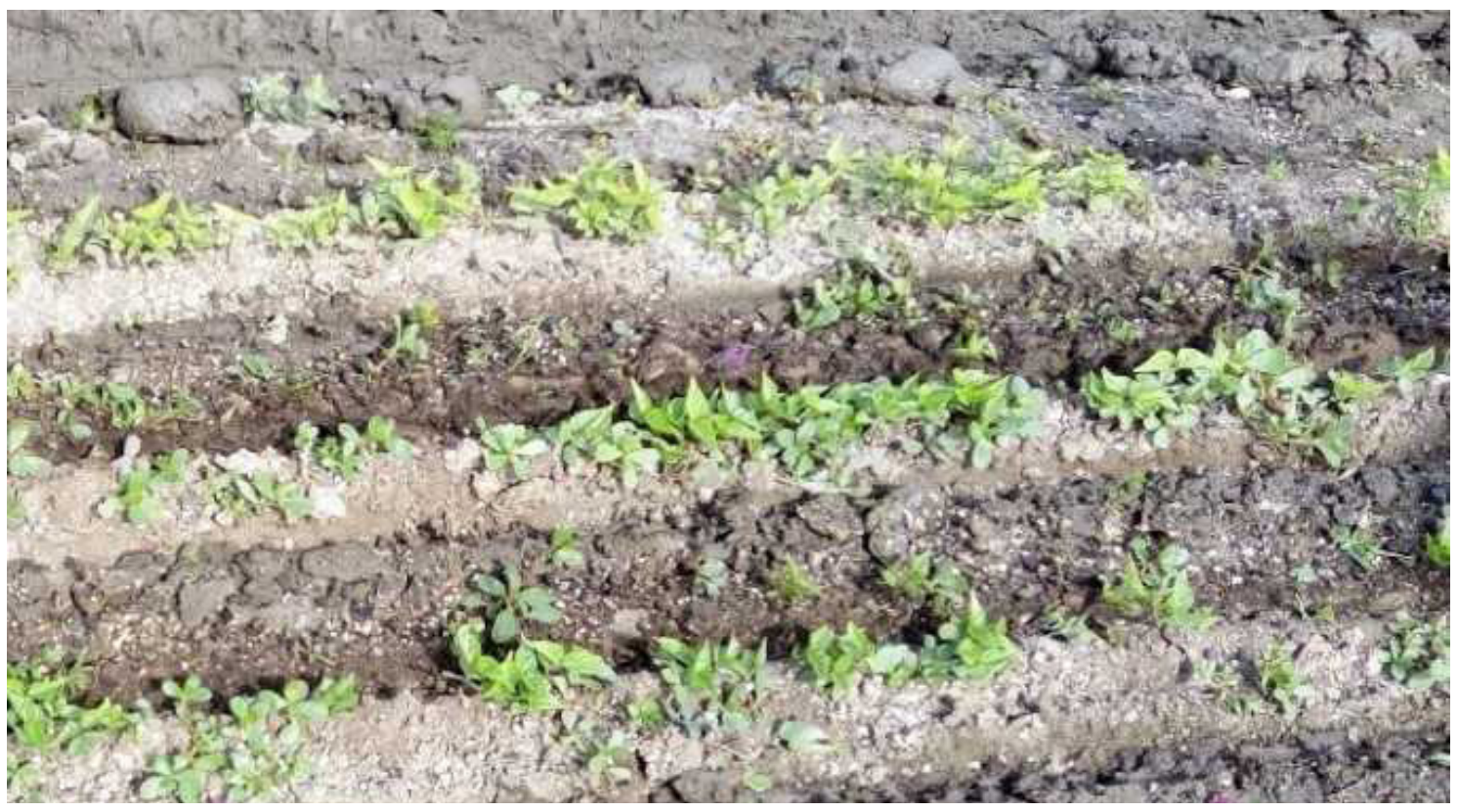

Şekil 3. Geniş yapraklı türde (Catalpa bignonioides) boyalı su testinin uygulaması

Figure 3. Application of colored water test on broadleaves (Catalpa bignonioides)

Yabancı ot ilacıyla yapılan denemelerde, ilaçlama sonrası yapılan gözlem ve tespitlerde ilaçlı uygulamanın başarılı olduğu ve boyalı su ile yapılan denemeye benzer sonuçların ortaya çıktığı görülmüştür. Beşer sıralı 90 m uzunluğundaki fidan yastıklarında yaklaşık 3.600 katalpa fidanı bulunmaktadir. Her iki denemede yastıklarda yapılan tam alandaki sayım sonucunda ortalama 73 adet fidanda bulaşma tespit edilmiş ve fidan kaybı da \%2 oranında gerçekleşmiştir (Şekil 3).

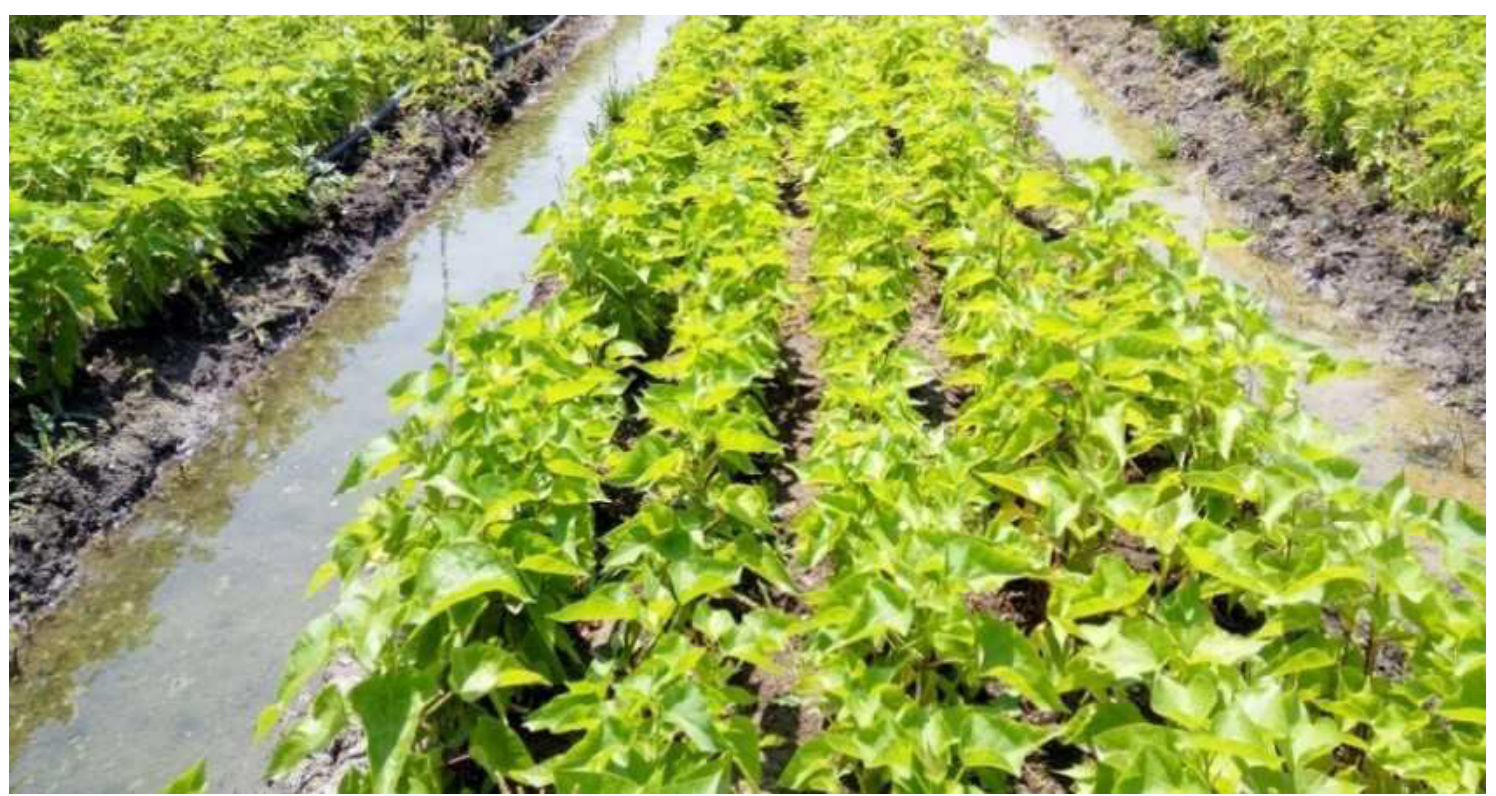

Şekil 4. İlaç uygulaması sonrası parselin görünümü

Figure 4. Appearance of the parcel after herbicide application 
Yastıklara bir kez ilaç uygulaması sonucunda bile yabancı ot çıkışı tamamen engellendiğinden ikinci kez ilaç uygulaması yapılmamıştır. Zira mayıs ayı içerisinde ilaçlama uygulaması yapılan katalpa fidanı bulunan yastıkta, ağustos ayında ve devamında yapılan gözlemlerde fidanların iyi gelişme gösterdiği, sıra aralarında herhangi bir yabancı ot gelişiminin görülmediği tespit edilmiştir (Şekil 4).

\section{Tartışma ve Sonuç}

Devlet Orman Fidanlıklarında yabancı otlarla mücadele için çekilebilir tip yastık ilaçlama ekipmanının kullanım maliyetini belirleme amacıyla yapılan bu çalışmada elde edilen bulgulara göre, EFRICAD ekipmanı için hesaplanan birim fiyat 165,58TL/da'dır. Buna karşılık, OGM verilerine göre hesaplanan toplam birim fiyat $2.142,00 \mathrm{TL} /$ da; yöresel koşullara göre hesaplanan toplam birim fiyat ise 2.245,20 TL/da'dır. Bu değerlere göre OGM birim fiyatları, EFRICAD ekipman1nın birim fiyatlarından 11,94 kat; yöresel koşullara göre hesaplanan birim fiyatlar ise 12,56 kat daha fazladır. İş gücü ile EFRICAD ekipmanı arasında oluşan bu birim fiyat farkının temel sebebi ot mücadelesi için çalışma yapılacak sahaya iş gücü ile beş kez girilmesine karşın, EFRICAD ekipmanı ile sadece bir kez girilmesinin yeterli olmasidır.

Muradiye (Manisa) Orman Fidanlık Șefliği üretim programında yer alan 50 da alanda üretilen $1+0$ yaşlı fidanların bulunduğu yastıklardaki yabancı otlarla mücadele işinde EFRICAD ekipmanının kullanılması ile bir vejetasyon döneminde OGM toplam masraflarına göre 98.821,00TL; yöresel koşullar dikkate alınarak hesaplanan masraflara göre ise $103.981,00 \mathrm{TL}$ tasarruf sağlanacağ çıkmaktadır.

Fidan üretim maliyetleri içinde yer alan yastık sıra aralarındaki yabancı otlarla mücadele maliyetinin düşürülebilmesi ancak bu mücadelenin makine ile gerçekleştirilmesiyle mümkündür. Geliştirilen bu ekipmanın kullanılacağı orman fidanlıklarında fidan yastıklarının iyi bir şekilde tesviye edilmesi, fidan sıra aralarının düzgün ve paralel tesis edilmesi ve traktör operatörünün ekipman kullanım deneyiminin artması ile birlikte çalışmanın sınırlılıklarını oluşturan etmenlerin bir kısmı ortadan kalkacak, fidan kayıpları ihmal edilebilir düzeye inecek ve ekipman verimi artacaktır.

$\mathrm{Bu}$ çalışmayla geliştirilen EFRICAD ekipmanının yöresel ve ülkesel ölçekte kullanımı ağaçlandırma çalışmalarımız için yetiştirilen milyonlarca fidanın daha düşük maliyetle üretilmesini sağlayacak, kimyasal ot mücadelesinin ise daha kolay ve ekonomik yapılmasına imkân verecektir. Aynı zaman- da fidanlıklarda ot alımlarının ve fidan bakımlarının zamanında yapılması ile yabancı ot rekabeti erken dönemde engellenecek ve fidan kalitesi arttırılmış olacaktır.

\section{Teşekkür}

Makalede, OGM tarafından desteklenen ve Ege Ormancılık Araştırma Enstitüsü Müdürlüğünce yürütülen "Orman Fidanlıkları İçin Çekilebilir Tip Yastık İlaçlama Ekipmanının Tasarımı ve Prototipinin Yap1lması" adlı ve 5.2112/2014-2016 numaralı araştırma projesine ait Proje Sonuç Raporundan (Boza ve ark., 2017) yararlanılmıştır. Verdikleri destekten dolayı Muradiye Orman Fidanlık Müdürü Nedim BOZKURT, Fidanlık Şefi Koray KALAY ve Müdürlük personeline teşekkür ederiz.

\section{Kaynaklar}

Acar, D., Tolunay, A., Alkan, H., 2004. Devlet orman fidanlık işletmelerinde maliyet yönetimi çabaları ve maliyet yönetiminin işletme başarısındaki rolü. Dokuz Eylül Üniversitesi, İktisadi ve İdari Bilimler Fakültesi Dergisi, 19(1), 101-118s.

Alkan, H., 2003. Maliyet Yönetim Aracı Olarak Hedef Maliyetleme ve Devlet Orman Fidanlık İşletmelerinde Uygulanabilirliği. Süleyman Demirel Üniversitesi Sosyal Bilimler Enstitüsü, İşletme Anabilim Dalı, Doktora Tezi, Isparta, 331s.

Anononim., 2004. Gelirler İdaresi Başkanlığı, T.C. Resmi Gazete, 25446 sayı, 28 Nisan 2004 tarih ve 333 Nolu Vergi Usul Kanunu Genel Tebliği

Anononim., 2005. Gelirler İdaresi Başkanlığı, T.C. Resmi Gazete, 5741 sayı, 28 Şubat 2005 tarih 345 Nolu Vergi Usul Kanunu Genel Tebliği

Anononim., 2016. Orman Genel Müdürlüğü, 2016 Y111 Analizli Birim Fiyat Cetveli. Muradiye Orman Fidanlık Şefliği Kayıtları

Anononim., 2018. Orman Genel Müdürlüğü, 2017 Y1l1 İdare Faaliyet Raporu, Strateji Geliştirme Dairesi Başkanlığ1, Ankara, 79s.

Boza, Z., Parlak, S., Göksu, E., Güven, M., Akkaş, M.E., Bozkurt, N., 2017. Orman Fidanlıkları İçin Çekilebilir Tip Yastık İlaçlama Ekipmanının Tasarımı ve Prototipinin Yapılması. Ege Ormancılık Araştırma Enstitüsü Müdürlüğü, Proje Sonuç Raporu (yayınlanmamış), İzmir, 56s.

İlter, E., Türegün, H., Yüksel, S., Savyer, S., Şirin, G., Çevik, İ., Acar, İ., Dinç, B.,1988. Fidanlıklarda Fidan Üretim Maliyetlerinin Saptanması Üzerine Araştırmalar, Ormancılık Araştırma Enstitüsü Yayınları, Teknik Bülten No: 198, Ankara, 47s.

Kavgacı, A., Yılmaz, E., Erkan, S., Divrik, A. K., Etli, T., Işık, A., Coşgun, S., Coşgun, U., Terzi, M., 2018. Fi- 
danlıklarda Yabancı Otlarla Mücadele Yöntemlerinin Belirlenmesi ve Kullanılan Yöntemlerin Fidanlık Maliyetlerine Katkılarının Araştırılması (Eğirdir ve Antalya Orman Fidanlık Müdürlükleri Örneği). Batı Akdeniz Ormancılık Araştırma Enstitüsü Müdürlüğü, Proje Sonuç Raporu (yayınlanmamış), Antalya, 34s.

Parlak S., 2016. Kültüre alınan Anacamptis sancta parsellerinde yabancı otlarla mücadelede kimyasal ve mekanik yöntemlerin etkinliğinin belirlenmesi, Orman Genel Müdürlüğü, Ormancılık Araştırma Dergisi, 4(1):126-133 DOI: http://dx.doi.org/10.17568/oad.13856

Ürgenç, S., 1998. Ağaç ve Süs Bitkileri Fidanlık ve Yetiştirme Tekniği, II. Bask1, Dilek Ofset Matbaacılık, İstanbul Üniversitesi Yayın No: 3395, Orman Fakültesi Yayın No: 442, ISBN 975-404-445-7, İstanbul, 717s. 